\title{
Multiple skeletal muscle metastases from poorly differentiated gastric adenocarcinoma
}

\author{
Yuki Koga, Yoshifumi Baba, Kazuto Harada, Keisuke Kosumi, Hironobu Shigaki, Junji Kurashige, Takatsugu Ishimoto, \\ Masaaki Iwatsuki, Yuji Miyamoto, Yasuo Sakamoto, Naoya Yoshida and Hideo Baba*
}

\begin{abstract}
We report here a rare case of gastric carcinoma with multiple intramuscular metastases. A 71-year-old man presented with rapidly evolving swelling of his left thigh and severe pain. Three years earlier, he had undergone neoadjuvant chemotherapy followed by gastrectomy for advanced gastric cancer. A computed tomography scan showed unusual swellings in multiple skeletal muscles with no vessel or bone invasion. Importantly, the affected muscles did not contain distinct masses but were diffusely enlarged. Pathological examination of an open muscle biopsy showed a poorly differentiated adenocarcinoma, supporting a diagnosis of gastric cancer metastases in multiple skeletal muscles.
\end{abstract}

Keywords: Gastric carcinoma; Skeletal muscle tumor; Metastasis

\section{Background}

Gastric cancer is the fourth commonest human malignant disease and the second commonest cause of cancer-related death worldwide [1]. Complete resection is essential for cure. Nonetheless, even after curative resection, $50-60 \%$ of patients relapse locally or with distant metastases. Gastric cancer has four broad patterns of recurrence: local recurrence either in the gastric bed or regional lymph nodes, peritoneal dissemination, liver metastasis, and distant metastasis. A Japanese study of 939 patients who had undergone surgery for gastric cancer found that recurrence was local in $22 \%$ of cases, peritoneal in $43 \%$, hepatic in $33 \%$, and distant in $21 \%$; $25 \%$ of patients had recurrences in multiple sites [2]. Reported cases of skeletal muscle metastases from gastric carcinoma are extremely rare. We report here a case of a patient with swelling in the thigh that was diagnosed as skeletal muscle metastases from gastric carcinoma.

\section{Case presentation}

A 71-year-old man presented with a rapidly evolving swelling of his left thigh and severe pain. The circumference of his left thigh was $56.7 \mathrm{~cm}$ and his right thigh was $36.8 \mathrm{~cm}$ (Fig. 1). Three years earlier, he had

* Correspondence: hdobaba@kumamoto-u.ac.jp

Department of Gastroenterological Surgery, Graduate School of Medical Science, Kumamoto University, 1-1-1 Honjo, Kumamoto 860-8556, Japan undergone preoperative chemotherapy (cisplatin + S1) and total gastrectomy for advanced gastric cancer. The tumor was completely resected, the pathological diagnosis being adenocarcinoma, and small clump of cancer cells having been found in the muscularis propria (pathological stage T2N0M0 (AJCC classification), pathological effect grade 2) (Fig. 2). Immunohistochemistry showed that the cancer cells were positive for HER2. The patient received no postoperative chemotherapy. At follow-up, 2 years after surgery, concentrations of the tumor markers carcinoembryonic antigen (CEA) and carbohydrate antigen 19-9 (CA19-9) had increased. A computed tomography $(\mathrm{CT})$ scan showed unusual swellings in multiple skeletal muscles (latissimus dorsi, transverse abdominal, iliac, iliopsoas, and femoral) with no vessel or bone invasion. Importantly, they did not contain distinct masses but were diffusely enlarged. A positron emission tomography (PET)-CT scan showed increased metabolic activity in these muscles. Magnetic resonance imaging (MRI) T1-weighted images showed heterogeneous intramuscular masses, whereas MRI T2-weighted images showed isosignal intensity. On MRI gadolinium-diethylene triamine pentaacetic acid (DTPA)-enhanced images, the intramuscular masses were enhanced with associated extensive peritumoral enhancement and central necrosis (Fig. 3). Our differential diagnosis included myositis, 


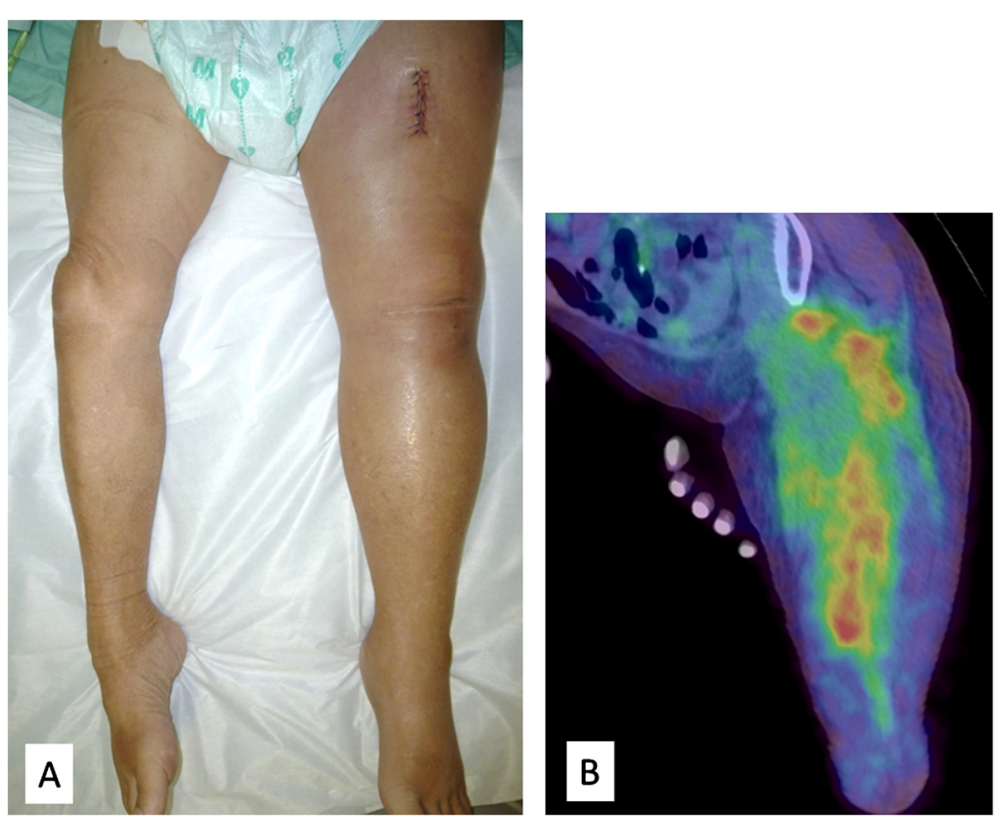

Fig. 1 Photograph and positron emission tomography-computed tomography (PET-CT) image of the left femur. a Swelling of the left femur. An open muscle biopsy was performed. b PET-CT scan image showing increased metabolic activity in multiple skeletal muscles (latissimus dorsi, transverse, iliac, iliopsoas, and femoral)

tubercular muscle abscess, primary soft-tissue sarcoma, and metastatic carcinoma. Pathological examination of an open muscle biopsy showed poorly differentiated adenocarcinoma, supporting a diagnosis of gastric cancer metastases in multiple skeletal muscles (Fig. 4). PET-CT scan showed no recurrent lesion other than multiple skeletal muscles. Based on pathological report demonstrating that the primary tumor was HER2-positive, the patient was commenced on chemotherapy with trastuzumab. However, as it turned out afterwards, cancer cells in the recurrent tumor were negative for HER2. In spite of this treatment, the concentrations of tumor markers (CEA and CA19-9) increased further, and the swellings in multiple skeletal muscles progressively enlarged. The patient died of respiratory failure with rapid collection of pleural effusion 54 days after admission, 18 days after establishment of the diagnosis of gastric cancer metastases.

\section{Discussion}

Skeletal muscle metastases are rare [3-5]; the reported incidence ranging from $0.16-0.03 \%$ in clinical practice and $0.8 \%$ in an autopsy study [6]. The most common malignancies that metastasize to skeletal muscle are lung cancer (25\%), gastrointestinal tumors (21\%), urological tumors (13\%), genital tumors (9.3\%), and breast cancer (8.2 \%) [7]. Muscle metastases most commonly occur in the lower limbs [5].

Gastric cancer rarely metastasizes to skeletal muscle, and such metastases are generally associated with widespread metastatic disease and poor prognosis. Because

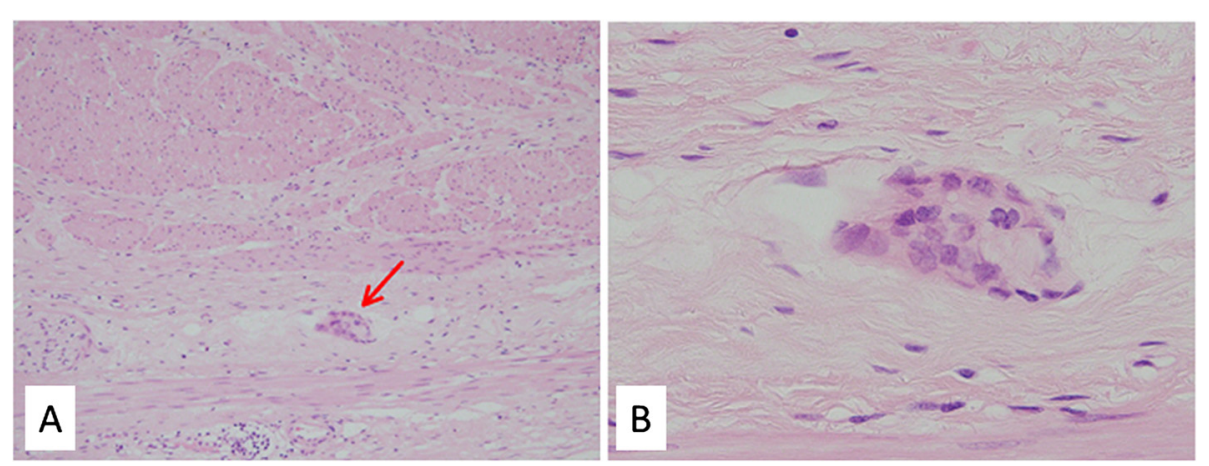

Fig. 2 Microscopic appearance of the resected stomach. a Small clump of cancer cells in the muscularis propria. b Magnified image of adenocarcinoma cells in the muscularis propria 


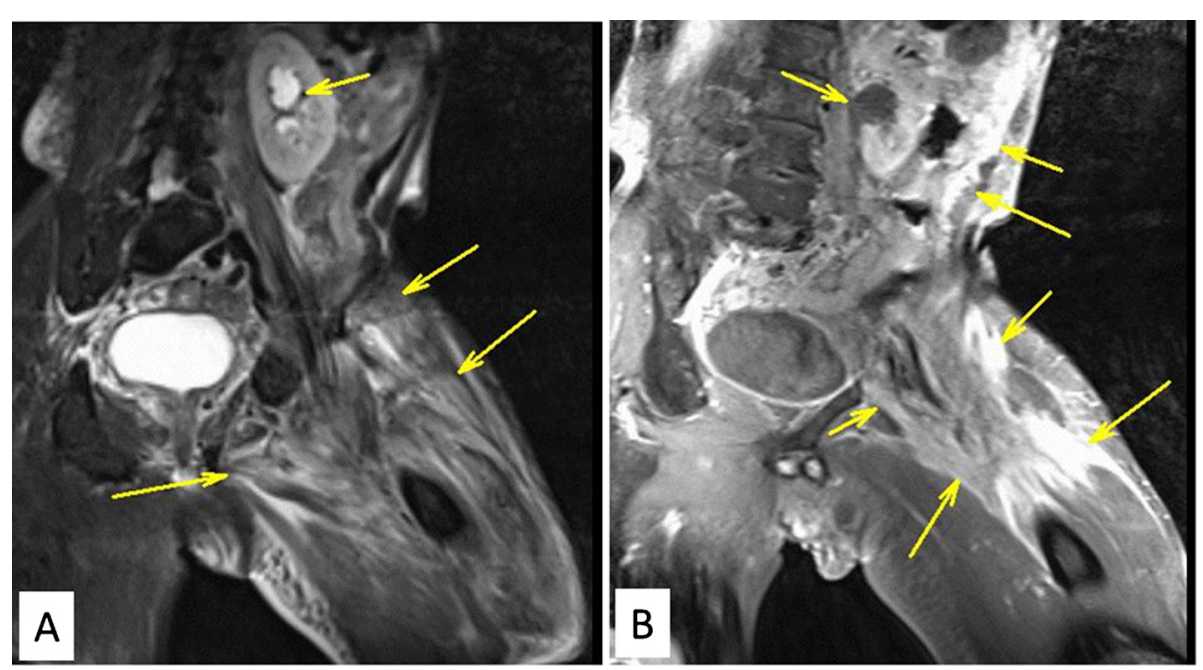

Fig. 3 Magnetic resonance imaging (MRI) T1- and T2-weighted images. a MRI T2-weighted image showing the intramuscular mass has isosignal intensity. b MRI T1-weighted images showing heterogeneous intramuscular masses

of their rarity and particular clinical characteristics, these metastases are challenging to diagnose [8]. To our knowledge, 21 cases of intramuscular metastases from gastric carcinoma, including our case, have been reported in the literature since 1970. These reported cases contain 17 males and 4 females, and their mean age was 62 years (range, 47-89 years) (Table 1) [3, 6, 8-24]. In some patients, including ours, metastases developed in multiple skeletal muscles. Our case was unusual for gastric carcinoma in that multiple muscle metastases developed without synchronous metastases to the liver or lungs. We were unable to determine the mechanism(s) of the metastases to skeletal muscle in our patient. However, given that skeletal muscle is a vascular tissue, we speculate that the mechanism of the muscle metastasis may be hematogenous.

Most skeletal muscle metastases are detected on CT scan because such scans are routinely performed for oncologic staging. Unenhanced CT scans show intramuscular metastatic masses as isodense lesions compared with the surrounding muscle tissue. MRI is considered superior to CT scanning for detecting and characterizing muscle abnormalities [4, 23, 25]. Metastases in muscle frequently have isointense signals and ill-defined margins on T1weighted MRI, whereas T2-weighted images generally show heterogeneous signal intensity with well-defined margins together with peritumoral edema [6, 25]. Tuoheti et al. showed that extensive peritumoral enhancement associated with central necrosis are characteristic features of skeletal muscle metastases on gadolinium-DTPAenhanced MRI, these characteristics being found in $92 \%$ of their cases [23]. Other features of intramuscular metastases include muscle enlargement, reticulated texture, and intratumoral patterns such as hemorrhage and central necrosis [12]. The radiological findings in our case were similar to those previously reported.

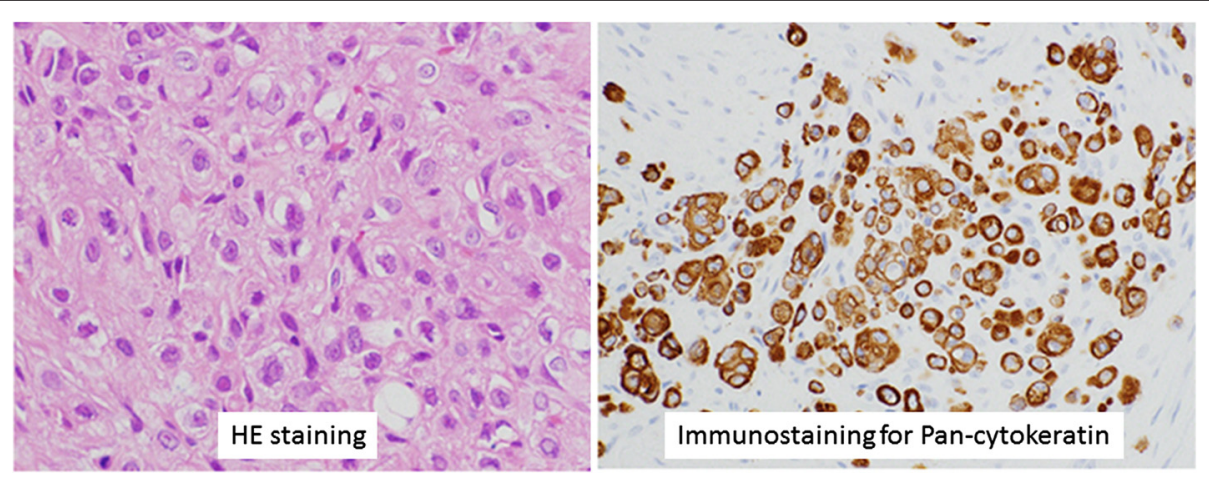

Fig. 4 Microscopic appearance of the metastatic adenocarcinoma in the femoral muscle. (Left) H\&E staining shows poorly differentiated adenocarcinoma. (Right) Positive immunohistochemistry for pan-cytokeratin 
Table 1 Reported cases of intramuscular metastasis from gastric carcinoma

\begin{tabular}{|c|c|c|c|c|c|c|c|c|}
\hline Author & Year & Age & Sex & Muscle site of metastasis & Other site of metastasis & Stage & Treatment & \\
\hline Traves et al. & 1979 & 52 & M & Psoas m. & N/A & N/A & N/A & [20] \\
\hline Obley et al. & 1983 & 54 & M & Paraspinal m. & N/A & N/A & N/A & [15] \\
\hline Rosenbaum et al. & 1984 & 54 & M & Upper arm m, femoral m. & $\mathrm{N} / \mathrm{A}$ & TXNXM1 & CRT & [3] \\
\hline Arnold et al. & 1989 & 59 & $\mathrm{~F}$ & Extraocular m. & N/A & N/A & N/A & [10] \\
\hline Porlie et al. & 1990 & 65 & M & Sartorius m., rectus femoris m. & No other metastasis & TXNXM1 & Chemotherapy & [17] \\
\hline Sudo et al. & 1993 & 61 & M & Trapezius m. & N/A & N/A & N/A & [18] \\
\hline Van Gelderen & 1993 & 47 & $\mathrm{~F}$ & Extraocular m. & N/A & N/A & N/A & [21] \\
\hline Toillon et al. & 1994 & 68 & M & Gastrocnemius m. & $\begin{array}{l}\text { LNs around the esophageal } \\
\text { hiatus and the celiac artery }\end{array}$ & TXNXM1 & Chemotherapy & [19] \\
\hline Amano et al. & 1996 & 57 & M & Gastrocnemius m. & $\mathrm{N} / \mathrm{A}$ & TXNXM1 & Chemotherapy and excision & [9] \\
\hline Narvaez et al. & 1998 & 49 & M & Psoas m. & N/A & N/A & N/A & [13] \\
\hline Pestalozzi et al. & 1998 & 72 & $\mathrm{~F}$ & Gastrocnemius m. & Mediastinal LNs & T4N1M0 & Excision and CRT & [16] \\
\hline Oba et al. & 2001 & 70 & M & Lumbar muscle & $\begin{array}{l}\text { Brain, lung, liver, bilateral adrenal } \\
\text { glands, supraclavicular } L N\end{array}$ & TXNXM1 & No treatment & [14] \\
\hline Kondo et al. & 2002 & 64 & $\mathrm{~F}$ & $\begin{array}{l}\text { Gluteus maximus } \mathrm{m} ., \\
\text { adductor magnus } \mathrm{m} \text {. }\end{array}$ & Abdominal wall & T4NOMO & Excision & {$[12]$} \\
\hline Touheti et al. & 2004 & 48 & M & Buttock & N/A & N/A & Excision & [23] \\
\hline Touheti et al. & 2004 & 89 & M & Shoulder & N/A & N/A & Excision & [23] \\
\hline Beşe NS et al. & 2006 & 67 & M & $\begin{array}{l}\text { Posterior right paralumbar m. } \\
\text { and posterior left paradorsal m. }\end{array}$ & Perigastric and lumboaortic LNs & Stage IV & Radiotherapy (palliative) & [24] \\
\hline D. Tougeron et al. & 2009 & 71 & M & Deltoid muscle & No other metastasis & T4N1M0 & Excision and CRT & {$[6]$} \\
\hline Pinelopi V et al. & 2012 & - & M & Muscles of the left thigh & No other metastasis & T3N1M0 & Excision & [11] \\
\hline Ilaria Pergolini et al. & 2014 & 47 & M & Gluteus m. & Lumboaortic LN & TXNXM1 & Chemotherapy & {$[8]$} \\
\hline Lourenco et al. & 2014 & 68 & M & Right thigh & No other metastasis & TXNXM1 & Chemotherapy & {$[22]$} \\
\hline Our case & 2015 & 71 & M & $\begin{array}{l}\text { Multiple (dorsal m., transverse } \\
\text { abdominal m., iliac m., } \\
\text { iliopsoas m., femoral m.) }\end{array}$ & No other metastasis & T2NOMO & Chemotherapy and excision & \\
\hline
\end{tabular}

Abbreviations: CRT chemoradiotherapy, LN lymph node, N/A not available

Therapeutic options for muscle metastases include radiotherapy, chemotherapy, and surgical excision $[4,23]$. Radiotherapy can relieve the pain and decrease the size of such lesions $[3,6,23,24]$. In carefully selected patients, surgical excision may help to relieve pain and prolong survival time. Chemotherapy, the only systemic option, is indicated when-as is usually the case-there is advanced disease with multiple metastatic sites $[4,23]$. In our case, chemotherapy with a molecularly targeted agent (trastuzumab) did not prolong our patient's life.

\section{Conclusions}

The diagnosis of skeletal muscle metastasis should be considered in the differential diagnosis of any painful soft tissue mass because there are no clinical or radiographic characteristics that distinguish metastatic carcinoma in muscle from soft tissue sarcomas. However, extensive peritumoral enhancement on MRI should suggest skeletal muscle metastases.

\section{Consent}

Written informed consent was obtained from the next of kin of the patient for publication of this case report and any accompanying images.

\section{Competing interests}

The authors declare that they have no competing interests.

\section{Authors' contributions}

YK, YB, KH, KK, HS, JK, TI, MI, YM, YS, NY, and HB participated in the treatment for this patient and drafted the manuscript. All authors read and approved the final manuscript.

Received: 29 July 2015 Accepted: 8 October 2015

Published online: 15 October 2015

\section{References}

1. Parkin DM, Bray F, Ferlay J, Pisani P. Global cancer statistics, 2002. CA Cancer J Clin. 2005;55(2):74-108.

2. Maehara Y, Hasuda S, Koga T, Tokunaga E, Kakeji Y, Sugimachi K. Postoperative outcome and sites of recurrence in patients following curative resection of gastric cancer. Br J Surg. 2000;87(3):353-7. doi:10.1046/ j.1365-2168.2000.01358.x.

3. Rosenbaum LH, Nicholas JJ, Slasky BS, Obley DL, Ellis LD. Malignant myositis ossificans: occult gastric carcinoma presenting as an acute rheumatic disorder. Ann Rheum Dis. 1984;43(1):95-7. 
4. Herring Jr CL, Harrelson JM, Scully SP. Metastatic carcinoma to skeletal muscle. A report of 15 patients. Clin Orthop Relat Res. 1998;355:272-81.

5. Seely S. Possible reasons for the high resistance of muscle to cancer. Med Hypotheses. 1980;6(2):133-7.

6. Tougeron D, Hamidou H, Dujardin F, Maillard C, Di Fiore F, Michel P. Unusual skeletal muscle metastasis from gastric adenocarcinoma. Gastroenterol Clin Biol. 2009;33(6-7):485-7. doi:10.1016/j.gcb.2009.03.018.

7. Surov A, Kohler J, Wienke A, Gufler H, Bach AG, Schramm D, et al. Muscle metastases: comparison of features in different primary tumours. Cancer Imaging. 2014;14:21. doi:10.1186/1470-7330-14-21.

8. Pergolini I, Crippa S, Santinelli A, Marmorale C. Skeletal muscle metastases as initial presentation of gastric carcinoma. Am J Case Rep. 2014;15:580-3. doi:10.12659/AJCR.891397.

9. Amano Y, Kumazaki T. Gastric carcinoma metastasis to calf muscles: MR findings. Radiat Med. 1996;14(1):35-6.

10. Arnold RW, Adams BA, Camoriano JK, Dyer JA. Acquired divergent strabismus: presumed metastatic gastric carcinoma to the medial rectus muscle. J Pediatr Ophthalmol Strabismus. 1989;26(1):50-1.

11. Gogou PV, Polydorou A, Papacharalampous XN, Kondi-Paphiti A, Balafouta MJ, Gennatas CS, et al. Femoral muscle metastasis from gastric carcinoma. Turk J Gastroenterol. 2012;23(5):611-2.

12. Kondo S, Onodera H, Kan S, Uchida S, Toguchida J, Imamura M. Intramuscular metastasis from gastric cancer. Gastric Cancer. 2002;5(2):107-11. doi:10.1007/ s101200200018.

13. Narvaez JA, Narvaez J, Clavaguera MT, Juanola X, Valls C, Fiter J. Bone and skeletal muscle metastases from gastric adenocarcinoma: unusual radiographic, CT and scintigraphic features. Eur Radiol. 1998;8(8):1366-9. doi:10.1007/s003300050554

14. Oba K, Ito T, Nakatani C, Okamura K, Yamaguchi H, Ajiro Y, et al. An elderly patient with gastric carcinoma developing multiple metastasis in skeletal muscle. J Nippon Med Sch. 2001;68(3):271-4.

15. Obley DL, Slasky BS, Peel RL, Rosenbaum LH, Nicholas JJ, Ellis LD. Bone-forming gastric metastases in muscle-computed tomographic demonstration. J Comput Tomogr. 1983;7(2):129-34

16. Pestalozzi BC, von Hochstetter AR. Muscle metastasis as initial manifestation of adenocarcinoma of the stomach. Schweiz Med Wochenschr. 1998;128(38):1414-7.

17. Porile $J$, Olopade OI, Hoffman PC. Gastric adenocarcinoma presenting with soft tissue masses. Am J Gastroenterol. 1990:85(1):76-7.

18. Sudo A, Ogihara Y, Shiokawa Y, Fujinami S, Sekiguchi S. Intramuscular metastasis of carcinoma. Clin Orthop Relat Res. 1993;296:213-7.

19. Toillon M, Lepage M, Naudin P, Moreau M, Trutaud-Muresan A, Lamotte A. Muscular metastasis from a gastric adenocarcinoma. Gastroenterol Clin Biol. 1994;18(10):906-7.

20. Treves RBD, Desproges-Gotteron R. Les metastases musculaires. Sem Hop Paris. 1979:55:1471-5.

21. Van Gelderen WF. Gastric carcinoma metastases to extraocular muscles. J Comput Assist Tomogr. 1993:17(3):499-500.

22. Lourenco LG, Carlotto JR, Herbella FA, Silva DA, Setti HB. Muscular metastasis from gastric cancer. J Gastrointest Oncol. 2014;5(6):E100-2. doi:10.3978/j.issn.2078-6891.2014.052.

23. Tuoheti Y, Okada K, Osanai T, Nishida J, Ehara S, Hashimoto M, et al. Skeletal muscle metastases of carcinoma: a clinicopathological study of 12 cases. Jpn J Clin Oncol. 2004;34(4):210-4.

24. Bese NS, Ozguroglu M, Dervisoglu S, Kanberoglu K, Ober A. Skeletal muscle: an unusual site of distant metastasis in gastric carcinoma. Radiat Med. 2006:24(2):150-3

25. Arpaci T, Ugurluer G, Akbas T, Arpaci RB, Serin M. Imaging of the skeletal muscle metastases. Eur Rev Med Pharmacol Sci. 2012:16(15):2057-63.

\section{Submit your manuscript to a SpringerOpen ${ }^{\circ}$ journal and benefit from:}

- Convenient online submission

- Rigorous peer review

- Immediate publication on acceptance

- Open access: articles freely available online

- High visibility within the field

- Retaining the copyright to your article

Submit your next manuscript at springeropen.com 